\title{
Botany
}

\section{Effects of one dark septate endophytic fungal and two Helotiales strains on the growth of Salix planifolia cuttings on iron ore waste rock}

\begin{tabular}{|c|c|}
\hline Journal: & Botany \\
\hline Manuscript ID & cjb-2021-0043.R2 \\
\hline Manuscript Type: & Article \\
\hline $\begin{array}{r}\text { Date Submitted by the } \\
\text { Author: }\end{array}$ & 24-May-2021 \\
\hline Complete List of Authors: & $\begin{array}{l}\text { Jean, Roudy; Université Laval, Département de Biologie; Université } \\
\text { Laval, Département de Biologie } \\
\text { Khasa, Damase; Université Laval, Sciences du bois et de la forêt } \\
\text { Boudreau, Stéphane; Université Laval, Biologie }\end{array}$ \\
\hline Keyword: & $\begin{array}{l}\text { Dark septate endophyte, Greenhouse experiment, Helotiales, Mining } \\
\text { substrates, Mycobionts controlled inoculation }\end{array}$ \\
\hline $\begin{array}{r}\text { Is the invited manuscript for } \\
\text { consideration in a Special } \\
\text { Issue? : }\end{array}$ & Not applicable (regular submission) \\
\hline
\end{tabular}

\section{SCHOLARONE ${ }^{m}$ Manuscripts}


Effects of one dark septate endophytic fungal and two Helotiales strains on the growth of Salix planifolia cuttings on iron ore waste rock

Roudy Jean ${ }^{1,2}$, Damase Phambu Khasa ${ }^{2}$, Stéphane Boudreau ${ }^{1,3}$

${ }^{1}$ Département de Biologie, Université Laval, Québec, (Québec), Canada

${ }^{2}$ Centre for Forest Research and Institute of Integrative Biology and Systems, Université Laval, Québec, QC, G1V 0A6

${ }^{3}$ Centre d'études nordiques, Université Laval, Canada

Corresponding author:

Roudy Jean, Département de Biologie, Université Laval, Québec, (Québec), Canada, Centre for Forest Research and Institute of Integrative Biology and Systems, e-mail: roudy.jean.1@ulaval.ca 


\begin{abstract}
Plants maintain beneficial mutualistic relationships with the mycobiont communities found in their rhizosphere, leading to an increase in plant productivity and health. In nutrient-depleted substrates like mine tailings, mycobiont inoculation is often recommended to help restore a successful plant cover. Our 15-week greenhouse experiment aimed to assess the individual effects of a dark septate endophyte (Phialocephala fortinii \#4; KX611529) and two Helotiales strains (Rhizoscyphus ericae \#22; EU221877 and Meliniomyces sp \#1; KT275679) on the growth of Salix planifolia cuttings on sterilized and unsterilized waste rock. Rhizoscyphus ericae increased cuttings shoot biomass on sterilized waste rock while Meliniomyces sp had a positive effect for cuttings grown on unsterilized waste rock. However, $P$. fortinii strain had no effect on the survival rate, shoot production, and biomass production of $S$. planifolia cuttings. This study demonstrates that controlled inoculation with ecologically well-adapted mycobionts could promote plant establishment and productivity on abandoned waste rock and be an efficient and integrated biotechnological approach for ecological restoration of canadian mining boreal ecosystems.
\end{abstract}

Keywords: Dark septate endophyte, Greenhouse experiment, Helotiales, Mining substrates, Mycobionts controlled inoculation, Willow cutting growth 


\section{INTRODUCTION}

In natural ecosystems, plants establish mutualistic symbioses with a wide spectrum of mycobionts to improve their productivity and overall health (Koziol et al. 2018). These interactions are an important driver of the composition and structure of plant communities (Johnson et al. 2004; Leake et al. 2004; Bennett et al. 2017). Mycorrhizal symbioses (Brundrett 2004; Khasa et al. 2009; Smith and Read 2010) and endophytic associations (Brundrett 2004; Schulz and Boyle 2006; Newsham 2011) are ubiquitous symbionts and are key components of terrestrial ecosystems. They provide plants with nutrients and increase their resistance to biotic (herbivory, diseases) and abiotic (drought, salinity, heavy metals) stressors (Brundrett 2004; Smith and Read 2010; Bücking et al. 2012; Vohník et al. 2013).

The strong demand for mineral resources over the last few decades resulted in habitat degradation (Hudson-Edwards et al. 2011; Walker 2012). For example, the removal of the topsoil to access the exploitable ore results in the destruction of the plant community and greatly reduces the abundance and diversity of mycorrhizal propagules (Bois et al. 2005; Schnoor et al. 2011; Verbruggen et al. 2013; Wang 2017; Hart et al. 2019). Moreover, mining activities generate large dumps of primary material (mine waste rock and finer mine tailings) with high concentrations of heavy metals (Cooke and Johnson 2002; Walker 2012), leading to a toxic biochemical environment unsuitable for natural plant colonization. As the reclamation of these dumps following mine closure is nowadays mandatory (Hilson 2000; Azcue 2012; Hessing and Summerville 2014), concrete actions are needed to restore the ecological functions and processes altered by mining operations. 
Ecological restoration practices often rely on the sowing of herbaceous species or on the planting of seedlings or cuttings of native woody species (Tordoff et al. 2000; Ruiz-Jaen and Mitchell Aide, 2005; Nadeau et al. 2016; Jean et al. 2020a; Jean et al. 2020b). Such practices can initiate plant succession and lead to the development of functional ecosystems (Tordoff et al. 2000; Cooke and Johnson 2002). Salix species are among the most used species for the reclamation of degraded mine tailings. Their rapid growth rate and high shoot and biomass production, their high rooting capacity, their high heavy metal uptake capacity, and tolerance to low $\mathrm{pH}$ as well as their ability to propagate vegetatively are all physiological and ecological traits well suited for reclamation project (Kuzovkina and Quigley 2005, Tharakan et al. 2005, Kuzovkina and Volk 2009; Jean et al. 2020a). Moreover, their ability to form associations with a wide array of ectomycorrhizal, arbuscular, and endophytic fungi species (Trowbridge and Jumpponen 2004; Regvar et al. 2010; Likar and Regvar 2013; Erlandson et al. 2016) could even promote their successful establishment on mine tailings (Robichaud et al. 2019).

Given their essential roles in functional ecosystems, restoration efforts should also aim to restore native mycorrhizal or endophytic fungal communities. Previous studies indicated that inoculation of native mycobionts, already adapted to the local environment, can promote vascular plant survival and growth on mine tailings (Bissonnette et al. 2014; Onwuchekwa et al. 2014; Maltz and Treseder 2015; Nadeau et al. 2018a, b; Robichaud et al. 2019). The use of mycobionts to increase plant performance is a compelling biotechnological approach to facilitate the reclamation of stressful mine wastes. However, the potential use of endophytic fungi and of ericoid or ecto-mycorrhizal species has been given little attention. With the expansion of mining activities in boreal and 
subarctic environments, it is becoming increasingly necessary to identify native mycobionts that could foster the restoration of native plant communities on mining waste dumps. In the Schefferville area, species such as Phialocephala fortinii C.J.K. Wang \& H.E. Wilcox, a dark septate endophyte (DSE), and Rhizoscyphus ericae D.J. Read and Meliniomyces sp \#1, two strains of Helotiales, are good candidates to form beneficial associations with Salix species. DSEs are widely distributed in the northern hemisphere where they colonize the root system of conifers, shrubs and herbaceous species (Rodriguez et al. 2009). However, their impact on plant mineral nutrition is still controversial (Newsham 2011; Mandyam and Jumpponen 2015), with studies reporting positive, neutral or negative effects of their presence on plant growth (Schulz and Boyle 2006; Newsham 2011; Mayerhofer et al. 2013; Mandyam and Jumpponen 2015). Among this group, $P$. fortinii is certainly one of the most studied species. Many species of the Helotiales Order, also found in the Schefferville area, have the potential to form functional ericoid mycorrhizas (with Ericaceae species) or ectomycorrhizas (with ectomycorrhizal plant species) (Vrålstad et al. 2002; Grelet et al. 2010; Vohník et al. 2013; Bruzone et al. 2015; Fadaei et al. 2020). Rhizoscyphus ericae and Meliniomyces sp are found in environments where edaphic conditions slow down the degradation process of organic matter and limit the capacity of plants to absorb soil nutrients.

The overall objective of this study was to evaluate the effect of inoculation of plane-leaved willow (Salix planifolia Pursch.) cuttings with P. fortinii C.J.K. Wang \& H.E. Wilcox, R. ericae D.J. Read and Meliniomyces sp \#1, in sterilized and unsterilized waste rock. Our research hypothesis states that inoculation will increase the performance of S. planifolia cuttings (survival, shoot and biomass production, and root colonization) 
by providing greater access to nutrients and greater tolerance to heavy metal toxicity. We predict that inoculated cuttings, regardless of the strain, would display greater survival, as well as higher shoot and biomass production compared to the control treatment. Moreover, given the ability of $R$. ericae and Meliniomyces $\mathrm{sp} \# 1$ to form functional ectomycorrhiza with ectomycorrhizal plant species, we also predicted that their beneficial effect on cutting performance will be greater than the one of $P$. fortinii.

\section{MATERIALS AND METHODS}

\section{Mining substrates and plant material}

For this experiment, we used waste rock collected from the Schefferville iron ore mine (for more detail, see Jean et al. 2020a). Prior to the experiment, we sterilized half of the waste rock with steam $\left(70^{\circ} \mathrm{C}\right)$ for a week to destroy all fungal propagules. As a result, the performance of $S$. planifolia cuttings grown in the sterilized waste rock should only vary according to the inoculation treatment (see below). The unsterilized waste rock was used as the control treatment.

For plant material, we used $25-\mathrm{cm}$ long cuttings of $S$. planifolia, taken from stems with a diameter ranging from 1.5 to $2.0 \mathrm{~cm}$. These stems were harvested near the iron ore mining site in the Schefferville area. Back at the university, they were stored in a cold room $\left(4^{\circ} \mathrm{C}\right)$ for 4 months before the start of the experiment to prevent desiccation or fungal development.

\section{Origin and preparation of fungal strains}

Three (3) fungal strains isolated by Côté (2019) were used to inoculate the S. planifolia cuttings: Rhizoscyphus ericae \#22 (EU221877), Meliniomyces sp \#1 (KT275679), and Phialocephala fortinii \#4 (KX611529) (See Table S1). 
For this study, these three fungal strains were obtained from healthy roots collected from plants growing on an undisturbed ecosystem adjacent to an iron ore mining site in the Schefferville area (subarctic Québec). After their isolation, they were grown on a GYME culture medium (Glucose Yeast Malt Extract) (see Quoreshi et al., 2005 for details). This solution was placed in 2L Erlenmeyer flasks ( 3 per isolate) and was autoclaved at $120^{\circ} \mathrm{C}$ for 15 minutes. After cooling, the fungal isolates were added to the flask and placed on an agitator (G10 Gyrotory Shaker) adjusted to a speed of 125 RPM, at room temperature $\left(25^{\circ} \mathrm{C}\right)$ for approximately 4 weeks. They were then transferred to sterile glass bottles and stored at $4^{\circ} \mathrm{C}$ until the inception of the experiment.

\section{Experimental design}

The experiment was designed to evaluate the impact of the inoculation of three fungal strains (P. fortinii, R. ericae and Meliniomyces sp) on the survival and shoot and biomass production of Salix planifolia cuttings grown on sterilized and unsterilized waste rock. Therefore, our design consisted of a 4 × 2 factorial experiment with four inoculation levels (P. fortinii, R. ericae, Meliniomyces sp, control) and two different substrates (sterilized and unsterilized waste rock) for a total of eight treatments (See Table S2). Each treatment was replicated six times (i.e. six blocks) for a total of 48 experimental units ( 8 treatments $* 6$ replicates). Treatments were applied randomly within the different blocks. The experimental unit corresponded to a mesocosm $(54 \mathrm{~cm}$ in length, $34 \mathrm{~cm}$ in width and $18 \mathrm{~cm}$ in height) filled with 15 liters of sterilized or unsterilized waste rock. Each mesocosm received three cuttings planted horizontally (Jean et al. 2020a) that were assigned to one inoculation treatment. Inoculation was done by soaking each cutting in $30 \mathrm{~mL}$ of one of the three mycelial solutions for two hours. The residual mycelial 
solution was poured over the cuttings once they were planted in the mesocosm. Cuttings of the control treatment were soaked in water to mimic the inoculation process.

The experiment was conducted in a greenhouse over a 15 wk-period (between April and July 2019). During the experiment, temperature was set at $22.5^{\circ} \mathrm{C}$ while the minimum ambient humidity was set at $60 \%$. In addition to natural daylight, greenhouse lamps were on for $15 \mathrm{~h}$ per day and provided an extra radiation intensity of 50 $\mu \mathrm{moles} / \mathrm{s} / \mathrm{m}^{2}$. Watering was provided by a drip irrigation system every other day.

\section{Measurement}

At the end of the experiment, a cutting was classified as dead if (i) it did not produce any shoot, (ii) had no living axillary bud; and (iii) was desiccated (Jean et al. 2020a). We decided to evaluate the survival rates at the cutting level $(n=144)$, even though three cuttings were planted in each experimental unit.

At the time of harvest, we took 3 soil samples per mesocosm to quantify $\mathrm{pH}$ and electrical conductivity using a pH meter (Combo, Hanna, USA). Afterwards, we removed the cuttings from the mesocosms by cutting (and counting) their shoots at the base. Roots were harvested carefully afterwards. Using a graduated ruler, we measured the length of the longest root in each mesocosm. Roots were then washed with running water and rinsed with distilled water. Biomass was dried at $65^{\circ} \mathrm{C}$ for $48 \mathrm{~h}$.

During root biomass harvesting, fine roots were selected to determine the colonization rate by the different fungal strains. These roots were washed with tap water and rinsed with distilled water. They were then soaked in a $10 \% \mathrm{KOH}$ solution for 1 hour at $90^{\circ} \mathrm{C}$ and rinsed again with tap water. The roots were then acidified in 5\% acetic acid at $90^{\circ} \mathrm{C}$ for $1 \mathrm{~h}$, rinsed again in tap water, and finally stained in trypan blue (Brundrett et 
al. 1996; Phillips and Hayman 1970). For each treatment, 50 randomly selected $0.5 \mathrm{~cm}$ root sections were placed on slides and examined under a light microscope. The observations were made following the method of enlarged intersections at $400 \mathrm{X}$ magnification (Giovannetti and Mosse 1980).

\section{Data analysis}

We carried out all the statistical analyses in SAS 9.4 (SAS Institute 2012) and effects were considered significant at $p \leq 0.05$.

For $\mathrm{pH}$ and electrical conductivity $(\mathrm{n}=48)$, we conducted ANOVAs with the SAS PROC MIXED procedure with the mining substrate and fungal strain as fixed effects and block as a random effect. Cutting survival was analyzed with a logistic regression analysis. To do so, we assigned a value of 1 to each cutting that was considered alive at the end of the experiment and a value of 0 to each dead cutting ( $n=144$, total number of cuttings).

For all other variables, we divided shoot and biomass production of the mesocosms by 3 to present an average performance per cutting. We discarded all mesocosms (10) where no cuttings were alive at the end of the experiment. These discarded mesocosms were well distributed throughout the different treatments. We conducted ANOVAs with the SAS PROC MIXED procedure using data from 38 mesocosms for shoot production, shoot and root biomass, maximum root length and root colonization rate. Mining substrate and fungal isolate were considered as fixed effects and block was considered as a random effect. When ANOVAs were significant, we conducted a Tukey test to identify significant differences between treatments $(p \leq 0.05)$. 
Moreover, we also performed simple contrasts to compare the significant differences between inoculation treatments since they were qualitatively structured. We carried out the following contrasts: Control vs Fungi, $P$. fortinii vs $R$. ericae * Meliniomyces sp \#1, R. ericae vs Meliniomyces $\mathrm{sp} \# 1$. We used the Shapiro-Wilk test to verify compliance with the residual normality and variance homogeneity assumptions.

\section{RESULTS}

\section{Mining substrate $\mathbf{p H}$ and electrical conductivity}

No significant interaction between the two factors (sterilization and inoculation) was detected for either electrical conductivity $(p=0.3944)$ or $\mathrm{pH}(p=0.9653)$ (see Table 1$)$. The waste rock sterilization factor had a significant effect on $\mathrm{pH}(p<0.0001)$ (Table 1$)$, with a higher $\mathrm{pH}$ for unsterilized waste rock $(4.84 \pm 0.25$, mean $\pm \mathrm{SE})$ compared to the sterilized one $(3.75 \pm 0.20)$; see Table 2$)$. Sterilization had no effect on electrical conductivity ( $p=0.3751)$. The inoculation factor had no significant effect on either electrical conductivity $(p=0.7557)$ or $\mathrm{pH}(p=0.9368)$ (see Table 1$)$.

\section{Cuttings survival}

No significant interaction between sterilization and inoculation was detected for cutting survival $\left(\chi^{2}=2.4460, p=0.4851\right)$. Moreover, neither factor had an effect on cutting survival (Inoculation treatments: $\chi^{2}=1.0266, p=0.7948$, Fig.1A; Sterilization: $\chi^{2}=$ $0.4139, p=0.5200$, Fig. 1B).

\section{Shoot per cutting and biomass production}

No significant interaction between sterilization and inoculation was detected for the number of shoots produced per cutting (see Table 1). Moreover, there was no statistical 
difference in the number of shoots per cutting for the inoculation factor $(p=0.8015$, Fig. 2A) nor the sterilization factor (see Table 1, Fig. 2B).

A significant interaction was detected between sterilization and inoculation treatments for root biomass (see Table 1). In unsterilized waste rock, dry root biomass was significantly higher when cuttings were inoculated with Meliniomyces sp \#1 compared to the control treatment (Fig. 3A). In sterilized waste rock however, root biomass was significantly higher when cuttings were inoculated with $R$. ericae than both the control treatment and the Meliniomyces sp \#1 treatment (Fig. 3A).

A significant interaction was also detected between sterilization and inoculation treatments for aboveground biomass $(p=0.0071$, see Table 1$)$. In unsterilized waste rock, aboveground biomass was higher following the inoculation with Meliniomyces sp \#1 when compared with the control treatment (Fig. 3B). However, in sterilized waste rock, inoculation treatments had no significant effect on aboveground biomass (Fig. 3B).

\section{Length and root colonization}

No significant interaction between sterilization and inoculation factors were detected for maximal root length $(p=0.453)$ (Fig. 4). Inoculation had, however, a significant impact on the maximal root length $(p=0.003)$ (See Table S3). However, maximal root length did not differ significantly between the fungal isolates, according to the contrast analysis (See Table S3). Sterilization had no impact on maximal root length $(p=0.308)$ (see Table $1)$.

A significant interaction was detected between sterilization and inoculation treatments for root colonization $(p<0.001)$ (Fig. 5). Root colonization was higher in sterilized waste rock than in unsterilized waste rock for cuttings inoculated with $P$. 
fortinii. However, root colonization was higher for the control treatment in unsterilized waste rock when compared to the sterilized waste rock. Overall, contrast analysis revealed that the colonization rate was significantly different between each inoculation level (P. fortinii $>$ R. ericae $>$ Meliniomyces sp \#1 > control) (See Table S3). Similar results were also observed in the sterilized waste rock (Fig. 5).

\section{DISCUSSION}

In this study, our objective was to identify the best fungal strain(s) to promote the survival and growth of $S$. planifolia cuttings on iron ore waste rock. Overall, our results suggest that the two of the three fungal strains tested had a beneficial effect on $S$. planifolia biomass production, although this effect was a function of the sterilization treatment.

Phialocephala fortinii being widely distributed in the northern hemisphere where it colonizes the root system of conifers, shrubs and herbaceous species (Grünig et al. 2008; Rodriguez et al. 2009), we expected a significant effect of this strain on the survival and growth of $S$. planifolia cuttings on waste rocks. In addition, under in vitro aseptic conditions, this DSE has demonstrated a high degree of tolerance to the stresses associated with these waste rocks (Côté 2019). However, in the present experiment, $P$. fortinii did not impact biomass production on any of the substrate, even though it was able to colonize the newly-developed roots of $S$. planifolia cuttings. This result suggests that $P$. fortinii had a neutral effect on the performance of the cuttings, a result that add to the controversial role of DSE. In fact, previous studies on the effects of DSE inoculation on plant growth, both under natural and in vivo or in vitro conditions, have reported positive (Schulz and Boyle 2006; Newsham 2011; Yamaji et al. 2016; Narisawa 2017), 
neutral (Schulz and Boyle 2006), or negative effects (Schulz and Boyle 2006; Tellenbach et al. 2011). These contrasting results seem to be partly explained by the substrate fertility (Newsham 2011; Berthelot et al. 2017). In studies where a significant positive effect was detected, it has been suggested that the DSE enhances plant growth by transferring nutrients to the host via the mineralization of organic matter (Narisawa 2017). Moreover, some studies have demonstrated that these mycobionts are effective in solubilizing $\mathrm{P}$ from organic sources, therefore increasing the availability of this element for the plants (Newsham 2011; Della Mónica et al. 2015). However, since the waste rocks used in this study had very low levels of nutrients and organic matter, it is likely that nutrient availability was simply not sufficient to allow mineralization and subsequent transfer to the plant. Further studies are therefore needed to ascertain the role of $P$. fortinii on mining substrate with and without organic and inorganic amendments. Secondly, such contrasting results also appear to be associated to host specificity, as the positive effects of $P$. fortinii was usually reported for strains that were isolated from the roots of the vascular plant species tested (Mayerhofer et al. 2013). As the strain tested in this study was isolated from the roots of Alnus crispa (See Table S1), this might explain the absence of a beneficial effect of $P$. fortinii inoculation treatment, as previously reported (Bruns et al. 2002; Lofgren et al. 2018). Future experiments should also aim to test if the effect of P. fortinii is "host dependent".

Contrary to $P$. fortinii, Meliniomyces sp \#1 and $R$. ericae strains had significant positive impacts on biomass production, although their effect varies with the sterilization treatment. Meliniomyces sp \#1 increased biomass production in unsterilized iron ore waste rock, while $R$. ericae increased it in sterilized one. This positive effect could be 
associated with a more efficient transfer of existing nutrients to the plants (Grelet et al. 2009) despite their low availability in the waste rock. By producing hyphae capable of exploring every nook and cranny of the mesocosm, these two strains become more efficient in the acquisition of the least available nutrients for the benefit of plant growth. In fact, cuttings inoculated with Meliniomyces sp \#1 and R. ericae had a greater root length than control ones, suggesting that the development of a deep and extensive root system triggers greater biomass production. An alternative explanation for the positive effect of these strains is the production of growth hormones (Aguilar-Trigueros and Rillig 2016). In fact, it has been suggested that many species of fungal symbionts produce growth hormones such as auxins, inducing beneficial effects on the development of their hosts (Ludwig-Müller 2000; Chanclud and Morel 2016).

The differential effect of Meliniomyces sp \#1 and R. ericae on sterilized and unsterilized substrates support the hypothesis that the overall effect of plant-mycobiont relationship depends on substrate properties as well as on the physiological traits of the mycobionts (Lennon et al. 2021; Erlandson et al. 2016). As a result, the effect of mycobionts can differ on a specific substrate and the effect of one specific mycobiont can differ between substrates. Previous studies have shown that plant-fungus interactions are in fact influenced by pH (Mayerhofer et al. 2013; Erlandson et al. 2016; Berthelot et al. 2017). Here, we observed a low $\mathrm{pH}$ of waste rock after sterilization, a result that could be associated with the production of organic acids compounds. This alteration of the substrate properties could explain the differential strain performance. An alternative explanation for the positive effect of $R$. ericae on sterilized waste rock is that the species referred to as the "Rhizoscyphus ericae aggregate" (Vrålstad et al. 2000) has been shown 
to significantly enhance the survival and growth of host plants, particularly in acidic soils with poor mineral nutrient availability. The "Rhizoscyphus ericae aggregate" includes both ectomycorrhizal and ericoid mycorrhizal species, including Cadophora finlandica and the two Meliniomyces species.

\section{CONCLUSION}

In this experiment, we explored the potential of beneficial symbiotic fungal inoculation to promote the growth of $S$. planifolia cuttings on mine waste rock. In a previous study, we were able to show that $S$. planifolia cuttings could grow on abandoned waste rocks and overburden from mining sites in the Schefferville area (Jean et al. 2020a). The next logical step in this work was to reintroduce native beneficial symbiotic fungi to increase the establishment, survival, and growth of these cuttings in harsh subarctic environments. In fact, two of the three strains tested, Meliniomyces sp and $R$. ericae, proved to be effective mycobionts as they increased the biomass production of S. planifolia cuttings, although their positive effects varied according to the substrate characteristics. Therefore, these two strains should be tested individually or as part of a consortium during field trials to evaluate their effects in field trials.

\section{ACKNOWLEDGMENTS}

This work was supported by a joint research program on sustainable development in the mining sector funded by Fonds de recherche du Québec - Nature et technologies (FRQNT) in collaboration with the Ministère de l'Énergie et des Ressources naturelles (MERN). Additional in-kind and logistical contributions from Tata Steel Minerals of Canada, T2 Environment and Viridis Terra International are acknowledged. 


\section{REFERENCES}

Aguilar-Trigueros, C.A., and Rillig, M.C. 2016. Effect of different root endophytic fungi on plant community structure in experimental microcosms. Ecol. Evol. 6(22): 8149-8158. doi: 10.1002/ece3.241

Azcue, J.M. 2012 Environmental impacts of mining activities: emphasis on mitigation and remedial measures. 1er ed. Springer Science \& Business Media.

Bennett, J.A., Maherali, H., Reinhart, K.O., Lekberg, Y., Hart., M.M., and Klironomos, J. 2017. Plant-soil feedbacks and mycorrhizal type influence temperate forest population endynamics. Science 355(6321): 181-184. doi: 10.1126 / science.aai 8212

Berthelot, C., Blaudez, D., and Leyval, C. 2017. Differential growth promotion of poplar and birch inoculated with three dark septate endophytes in two trace elementcontaminated soils. Int. J. Phyto. 19(12): 1118-

1125.doi.org/10.1080/15226514.2017.1328392

Berthelot, C., Leyval, C., Foulon, J., Chalot, M., and Blaudez, D. 2016. Plant growth promotion, metabolite production and metal tolerance of dark septate endophytes isolated from metal-polluted poplar phytomanagement sites. FEMS Micro.

Ecol. 92(10). doi.org/10.1093/femsec/fiw144

Bissonnette, C., Fahlman, B., Peru, K.M., Khasa, D.P., Greer, C.W., Headley, J.V., and Roy, S. 2014. Symbiosis with Frankia sp. benefits the establishment of Alnus viridis ssp. crispa and Alnus incana ssp. rugosa in tailings sand from the Canadian oil sands industry. Ecol. Eng. 68:167-175. doi.org/10.1016/j.ecoleng.2014.03.061 
Bois, G., Piché, Y., Fung, M.Y.P., and Khasa, D.P. 2005. Mycorrhizal inoculum potentials of pure reclamation materials and revegetated tailing sands from the Canadian oil sand industry. Mycorrhiza. 15(3): 149-158. doi 10.1007/s00572004-0315-4

Brundrett, M. 2004. Diversity and classification of mycorrhizal associations. Bio. Rev. 79(3): 473-495. doi-org/10.1017/s1464793103006316

Brundrett, M., Bougher, N., Dell, B., Grove, T., and Malajczuk, N. 1996. Working with mycorrhizas in forestry and agriculture. Canberra: Austra. Cent. Inter. Agri. Resear. No.34.

Bruns, T.D., Bidartondo, M.I., and Taylor, D.L. 2002. Host specificity in ectomycorrhizal communities: what do the exceptions tell us? Integr. Comp. Bio. 42(2): 352-359. doi.org/10.1093/icb/42.2.352

Bruzone, M.C., Fontenla, S.B., and Vohník, M. 2015. Is the prominent ericoid mycorrhizal fungus Rhizoscyphus ericae absent in the Southern Hemisphere's Ericaceae? A case study on the diversity of root mycobionts in Gaultheria spp. from northwest Patagonia, Argentina. Mycorrhiza. 25(1): 25-40. doi $10.1007 / \mathrm{s} 00572-014-0586-3$

Bücking, H., Liepold, E., and Ambilwade, P. 2012. The role of the mycorrhizal symbiosis in nutrient uptake of plants and the regulatory mechanisms underlying these transport processes. Plant Sci. 4 :108-132. doi:10.5772/52570

Chanclud, E., and Morel, J.B. 2016. Plant hormones: a fungal point of view. Mol. Plant Patho. 17(8): 1289 -1297. doi.org/10.1111/mpp.12393 
Cooke, J.A., and Johnson, M.S. 2002. Ecological restoration of land with particular reference to the mining of metals and industrial minerals: A review of theory and practice. Environ. Rev. 10(1): 41-71. doi 10.1139/a01-014

Côté, L. 2019. Sélection de symbiotes racinaires pour la restauration écologique de résidus miniers dans le nord du Québec. Mémoire de Maîtrise, Département des sciences du bois et de la forêt, Québec, QC.

Della Mónica, I.F., Saparrat, M.C., Godeas, A.M., and Scervino, J.M. 2015. The coexistence between DSE and AMF symbionts affects plant $\mathrm{P}$ pools through $\mathrm{P}$ mineralization and solubilization processes. Fungal Ecol. 17: 10-17. doi.org/10.1016/j.funeco.2015.04.004

Erlandson, S.R., Savage, J.A., Cavender-Bares, J.M., and Peay, K.G. 2016. Soil moisture and chemistry influence diversity of ectomycorrhizal fungal communities associating with willow along an hydrologic gradient. FEMS Micro. Ecol. 92(1). doi.org/10.1093/femsec/fiv148

Fadaei, S., Vaziriyeganeh, M., Young, M., Sherr, I., and Zwiazek, J.J. 2020. Ericoid mycorrhizal fungi enhance salt tolerance in ericaceous plants. Mycorrhiza. 30(4):419-429. doi.org/10.1007/s00572-020-00958-8

Giovannetti, M., and Mosse, B. 1980. An evaluation of techniques for measuring vesicular arbuscular mycorrhizal infection in roots. New Phytol. 489-500.

Grelet, G.A., Johnson, D., Paterson, E., Anderson, I.C., and Alexander, I.J. 2009. Reciprocal carbon and nitrogen transfer between an ericaceous dwarf shrub and fungi isolated from Piceirhiza bicolorata ectomycorrhizas. New Phytol. 182(2): 359-366. doi.org/10.1111/j.1469-8137.2009.02813. 
Grelet, G.A., Johnson, D., Vrålstad, T., Alexander, I.J., and Anderson, I.C. 2010. New insights into the mycorrhizal Rhizoscyphus ericae aggregate: spatial structure and co-colonization of ectomycorrhizal and ericoid roots. New Phytol. 188(1): 210222. doi: $10.1111 / \mathrm{j} .1469-8137.2010 .03353 . \mathrm{x}$

Grünig, C.R., Queloz, V., Sieber, T.N., and Holdenrieder, O. 2008. Dark septate endophytes (DSE) of the Phialocephala fortinii sl-Acephala applanata species complex in tree roots: classification, population biology, and ecology. Bot. 86(12): 1355-1369. doi.org/10.1139/b08-108

Hart, M., Gorzelak, M., Mcammond, B.M., Van Hamme, J.D., Stevens, J., Abbott, L.K., Whiteley, A.S., and Nevill, P. 2019. Fungal communities resist recovery in sand mine restoration. Front Forests Global Change 2: 78. doi.org/10.3389/ffgc. 2019.00078

Hessing, M., and Summerville, T. 2014. Canadian natural resource and environmental policy: political economy and public policy. $2^{\text {nd }}$ ed. UBC Press, Canada. $369 p$.

Hilson, G. 2000. Sustainable development policies in Canada's mining sector: an overview of government and industry efforts. Environ. Sci. Pol. 3(4): 201-211. doi.org/10.1016/s1462-9011(00)00086-1

Hudson-Edwards, K.A., Jamieson, H.E., and Lottermoser, B.G. 2011. Mine wastes: past, present, future. Elements 7(6): 375-380. DOI: 10.2113/gselements.7.6.375

Jean, R., Khasa, D.P., and Boudreau, S. 2020a. The Effect of Planting Orientation and Iron Ore Mining Substrates on the Survival and Growth of Salix planifolia Cuttings in a Greenhouse Experiment. Ecol. Restor. 38(3): 153-159. doi:muse.jhu.edu/article/763077 
Jean, R., Khasa, D.P., and Boudreau, S. 2020b. Could Biochar and Peat Moss Help Address Reclamation Challenges of Using Shrub Species on Overburden Dumps from a Subarctic Iron Mine? Ecol Restor. 38(4): 207-210

Johnson, D., Vandenkoornhuyse, P.J., Leake, J.R., Gilbert, L., Booth, R.E., Grime, J.P., and Read, D.J. 2004. Plant communities affect arbuscular mycorrhizal fungal diversity and community composition in grassland microcosms. New Phytol: 161(2): 503-515. doi.org/10.1046/j.1469-8137.2003.00938.x

Khasa, D.P., Piché, Y., and Coughlan, A.P. 2009. Advances in mycorrhizal science and technology. 1er ed. NRC Research Press. 198p.

Koziol, L., Schultz, P.A., House, G.L., Bauer, J.T., Middleton, E.L., and Bever, J.D. 2018. The plant microbiome and native plant restoration: the example of native mycorrhizal fungi. BioScie: 68(12): 996-1006. doi:10.1093/biosci/biy125

Kuzovkina, Y.A., and Quigley, M.F. 2005. Willows beyond wetlands: uses of Salix L. species for environmental projects. Water Air Soil Pollu. 162(1):183-204. Doi: $10.1007 / \mathrm{s} 11270-005-6272-5$

Kuzovkina, Y.A., and Volk, T.A. 2009. The characterization of willow (Salix L.) varieties for use in ecological engineering applications: co-ordination of structure, function and autecology. Ecol. Eng. 35(8): 1178-1189. doi.org/10.1016/i.ecoleng.2009.03.010

Leake, J., Johnson, D., Donnelly, D., Muckle, G., Boddy, L., and Read, D. 2004. Networks of power and influence: the role of mycorrhizal mycelium in controlling plant communities and agroecosystem functioning. Can. J. Bot. 82(8): 10161045. doi: 10.1139/b04-060 
Lennon, J. T., Aanderud, Z. T., Lehmkuhl, B. K., and Schoolmaster Jr, D. R. 2012. Mapping the niche space of soil microorganisms using taxonomy and traits. Ecol. 93(8): 1867-1879. doi.org/10.1890/11-1745.

Likar, M., and Regvar, M. 2013. Isolates of dark septate endophytes reduce metal uptake and improve physiology of Salix caprea L. Plant Soil 370(1): 593-604. doi:10.1007/s11104-013-1656-6

Lofgren, L., and Nguyen, N.H., and Kennedy, P.G. 2018. Ectomycorrhizal host specificity in a changing world: can legacy effects explain anomalous current associations? New Phytol. 220(4): 1273-

1284. doi.org/10.1111/nph.15008Ludwig-Müller, J. 2000. Hormonal balance in plants during colonization by mycorrhizal fungi. In Arbuscular mycorrhizas: physiology and function. 1er ed. Springer, Dordrecht. pp. 263-285.

Maltz, M.R., and Treseder, K.K. 2015. Sources of inocula influence mycorrhizal colonization of plants in restoration projects: a meta-analysis. Restor. Ecol. 23(5): 625-634.doi: 10.1111/rec.12231

Mandyam, K.G., and Jumpponen, A. 2015. Mutualism-parasitism paradigm synthesized from results of root-endophyte models. Front Microb 5:776. doi.org/10.3389/fmicb.2014.00776

Mayerhofer, M.S., Kernaghan, G., and Harper, K.A. 2013. The effects of fungal root endophytes on plant growth: a meta-analysis. Mycorrhiza. 23(2):119-128. doi :10.1007/s00572-012-0456-9 
Mitchell, D.T., and Gibson, B.R. .2006. Ericoid mycorrhizal association: ability to adapt to a broad range of habitats. Mycorrhiza. 20(1): 2-9. doi.org/10.1016/j.mycol.2005.11.015

Nadeau, B.N., Quoreshi, A., and Khasa, D.P. 2016. Ecological Restoration and Bioremediation of Canadian Mining Boreal Ecosystems. In Microbes for Restoration of Degraded Ecosystems. 1er ed. New India Publishing Agency, Bangalore, India. pp. 259-284.

Nadeau, M.B., Laur, J., and Khasa, D.P. 2018a. Mycorrhizae and rhizobacteria on Precambrian rocky gold mine tailings: I. Mine-adapted symbionts promote white spruce health and growth. Front Plant Sci 9: 267. doi.org/10.3389/fpls.2018.01267

Nadeau, M.B., Laur, J., and Khasa, D.P. 2018b. Mycorrhizae and Rhizobacteria on Precambrian Rocky Gold Mine Tailings: II. Mine-Adapted Symbionts Alleviate Soil Element Imbalance for a Better Nutritional Status of White Spruce Seedlings. Front. Plant Sci. 9:1268. doi: 10.3389/fpls.2018.01268

Narisawa, K. 2017. The dark septate endophytic fungus Phialocephala fortinii is a potential decomposer of soil organic compounds and a promoter of Asparagus officinalis growth. Fungal Ecol. 28:1-10. doi.org/10.1016/j.funeco.2017.04.001

Newsham, K.K. 2011. A meta-analysis of plant responses to dark septate root endophytes. New Phytol. 190(3): 783-793. doi.org/10.1111/j.1469$\underline{8137.2010 .03611 . x}$

Onwuchekwa, N.E., Zwiazek, J.J., Quoreshi, A., Khasa, D.P. 2014. Growth of mycorrhizal jack pine (Pinus banksiana) and white spruce (Picea glauca) 
seedlings planted in oil sands reclaimed areas. Mycorrhiza. 24(6):431-441. doi 10.1007/s00572-014-0555-x.

Phillips, J.M., and Hayman, D.S. 1970. Improved procedures for clearing roots and staining parasitic and vesicular-arbuscular mycorrhizal fungi for rapid assessment of infection. Transact. British Myco. Soc.55(1): 158-161.

Quoreshi, A.M., Khasa, D.P., Bois, G., Jany, J.L., Begrand, E., McCurdy, D., Fung, M. 2005. Mycorrhizal biotechnology for reclamation of oil sand composite tailings and tailings land in Alberta. Thin Green Line 117.

Regvar, M., Likar, M., Piltaver, A., Kugonič, N., and Smith, J.E. 2010. Fungal community structure under goat willows (Salix caprea L.) growing at metal polluted site: the potential of screening in a model phytostabilisation study. Plant Soil 330(1): 345-356. doi :10.1007/s11104-009-0207-7

Robichaud, K., Girard, C., Dagher, D., Stewart, K., Labrecque, M., Hijri, M., and Amyot, M. 2019. Local fungi, willow and municipal compost effectively remediate petroleum-contaminated soil in the Canadian North. Chem. 220: 47-55. doi.org/10.1016/j.chemosphere.2018.12.108

Rodriguez, R.J., White Jr,J F., Arnold, A.E., and Redman, A.R.A. 2009. Fungal endophytes: diversity and functional roles. New Phytol. 182(2): 314-330. doi.org/10.1111/j.1469-8137.2009.02773.x

Ruiz-Jaen, M.C., and Mitchell Aide, T. 2005. Restoration success: how is it being measured? Restor. Ecol. 13(3): 569-577. doi.org/10.1111/j.1526100x.2005.00072.x

Smith, S.E., and Read, D.J. 2010. Mycorrhizal symbiosis. 3rd ed. Academic press. 803p. 
Schnoor, T.K., Lekberg, Y., Rosendahl, S., and Olsson, P.A. 2011. Mechanical soil disturbance as a determinant of arbuscular mycorrhizal fungal communities in semi-natural grassland. Mycorrhiza. 21(3): 211-220. doi 10.1007/s00572-0100325-3

Schulz, B., and Boyle, C. 2006. What are endophytes? In Microbial root endophytes. 1er ed. Springer, Berlin, Heidelberg. pp. 1-13

Tharakan, P.J., Volk, T.A., Nowak, C.A., and Abrahamson, L.P. 2005. Morphological traits of 30 willow clones and their relationship to biomass production. Can. J. For. Res. 35(2): 421-431. doi-org./10.1139/x04-195

Tellenbach, C., Grünig, C.R., Sieber, T.N. 2011. Negative effects on survival and performance of Norway spruce seedlings colonized by dark septate root endophytes are primarily isolate-dependent. Environ. Micro. 13(9): 2508-2517. doi:10.1111/j.1462-2920.2011.02523.x

Tordoff, G.M., Baker, A.J.M., and Willis, A.J. 2000. Current approaches to the revegetation and reclamation of metalliferous mine wastes. Chemo. 41(1-2): 219228. doi.org/10.1016/s0045-6535(99)00414-2

Trowbridge, J., and Jumpponen, A. 2004. Fungal colonization of shrub willow roots at the forefront of a receding glacier. Mycorrhiza. 14(5): 283293.doi :10.1007/s00572-003-0264-3

Verbruggen, E., van der Heijden, M.G., Rillig, M.C., and Kiers, E.T. 2013. Mycorrhizal fungal establishment in agricultural soils: factors determining inoculation success. New Phytol. 197(4): 1104-1109. doi.org/10.1111/j.1469$\underline{\text { 8137.2012.04348.x }}$ 
Vrålstad, T., Fossheim, T., and Schumacher, T. 2000. Piceirhiza bicolorata the ectomycorrhizal expression of the Hymenoscyphus ericae aggregate? New Phytol. 145(3): 549-563. doi.org/10.1046/j.1469-8137.2000.00605.x

Vrålstad, T., Myhre, E., and Schumacher, T. 2002. Molecular diversity and phylogenetic affinities of symbiotic root-associated ascomycetes of the Helotiales in burnt and metal polluted habitats. New Phytol. 155(1): 131-148. doi.org/10.1046/j.1469$\underline{8137.2002 .00444 . \mathrm{x}}$

Vohník, M., Mrnka, L., Lukešová, T., Bruzone, M.C., Kohout, P., and Fehrer, J. 2013. The cultivable endophytic community of Norway spruce ectomycorrhizas from microhabitats lacking ericaceous hosts is dominated by ericoid mycorrhizal Meliniomyces variabilis. Fungal Ecol. 6(4): 281-292. doi.org/10.1016/j.funeco.2013.03.006

Walker, L.R. 2012. The biology of disturbed habitats. 1er ed. Oxford University Press, New York, USA. 319p.

Wang, F. 2017. Occurrence of arbuscular mycorrhizal fungi in mining-impacted sites and their contribution to ecological restoration: Mechanisms and applications. Crit. Rev. Environ. Sci. Techno., 47(20): 1901-1957. doi.org/10.1080/10643389.2017.1400853

Yamaji, K., Watanabe, Y., Masuya, H., Shigeto, A., Yui, H., and Haruma, T. 2016. Root fungal endophytes enhance heavy-metal stress tolerance of Clethra barbinervis growing naturally at mining sites via growth enhancement, promotion of nutrient uptake and decrease of heavy-metal concentration. PloS One 11. doi:10.1371/journal.pone.0169089. 


\section{Tables and figures}

Table 1. Analysis of variance (ANOVA) showing the fixed effects of substrate and fungal factors and their interactions for the variables $\mathrm{pH}$, electrical conductivity, shoot production, aboveground biomass, root biomass, maximal root length and root colonization (Significance level: $p \leq 0.05$ )

Table 2. Mining substrate $\mathrm{pH}$ and electrical conductivity. No significant interactions were detected for any of the variables ( $\mathrm{pH}: p=0.9653$; EC: $p=0.3944)$.

Figure 1. Survival rates of cuttings according to (A) Inoculation treatment (P. fortinii: Phialocephala fortinit, R. ericae: Rhizoscyphus ericae) and (B) Sterilization treatment (Control: Unsterilized waste rock, sterilized: Sterilized waste rock) (mean \pm standard error, for each factor, no statistically significant effect was detected, $p<0.05$; logistic regression analysis).

Figure 2. Shoot production per cutting of S. planifolia in (A) Inoculation treatment $(P$. fortinii: Phialocephala fortinii, R. ericae: Rhizoscyphus ericae) and (B) Sterilization treatment (Control: Unsterilized waste rock, sterilized: Sterilized waste rock) (mean \pm standard error; for each factor, no statistically significant effect was detected, $p<0.05$; Tukey test, $p<0.05)$.

Figure 3. A) Root biomass, B) Aboveground biomass from cuttings of S. planifolia in the Inoculation treatment and in the Sterilization treatment (mean \pm standard error). Black bars: control: unsterilized waste rock, White bars with dark outlines: sterilized: sterilized 
waste rock. Different lowercase letters indicate the presence of significant differences (Tukey test, $p<0.05$ ).

Figure 4. Root length from cuttings of S. planifolia in the Inoculation treatment and in the Sterilization treatment (mean \pm standard error; for each factor, no statistically significant interaction was detected, $p<0.05$; Tukey test, $p<0.05$ ). Black bars: control: unsterilized waste rock, White bars with dark outlines: sterilized: sterilized waste rock.

Figure 5. Colonization rate of roots from cuttings of S. planifolia in the Inoculation treatment and in the Sterilization treatment (mean \pm standard error). Black bars: control: unsterilized waste rock, White bars with dark outlines: sterilized: sterilized waste rock. Different lowercase letters indicate the presence of significant differences (Tukey test, $p$ $<0.05)$ 
Table 1. Analysis of variance (ANOVA) showing the fixed effects of substrate and fungal factors and their interactions for the variables $\mathrm{pH}$, electrical conductivity, shoot production, aboveground biomass, root biomass, maximal root length and root colonization (Significance level: $\mathrm{p} \leq 0.05$ )

\begin{tabular}{rcccccc}
\hline & \multicolumn{2}{c}{ Sterilization } & \multicolumn{2}{c}{ Inoculation } & \multicolumn{2}{c}{ Ster. * Inoc. } \\
\cline { 2 - 7 } & $\mathrm{F}$ & $p$ & $\mathrm{~F}$ & $p$ & $\mathrm{~F}$ & $p$ \\
\cline { 2 - 7 } $\mathrm{pH}$ & 63.42 & $<0.001^{* * *}$ & 0.14 & 0.937 & 0.09 & 0.965 \\
Electrical cond. & 0.81 & 0.375 & 0.40 & 0.756 & 1.02 & 0.394 \\
Shoot production & 0.13 & 0.721 & 0.33 & 0.802 & 1.47 & 0.248 \\
Abovegr. biomass & 1.13 & 0.298 & 2.43 & 0.088 & 5.06 & $0.007^{* *}$ \\
Root biomass & 3.74 & 0.065 & 3.99 & $0.019^{*}$ & 11.61 & $<0.001^{* * *}$ \\
Max. root length & 1.08 & 0.308 & 6.29 & $0.003^{* *}$ & 0.90 & 0.453 \\
Root colonization & 0.15 & 0.702 & 49.02 & $<0.001^{* * *}$ & 10.11 & $<0.001^{* * *}$ \\
\hline$P<0.001^{* * * *}, P<0.01$ & ${ }^{* * \prime}, P<0.05^{* *}$ & & & & &
\end{tabular}


Table 2. Mining substrate $\mathrm{pH}$ and electrical conductivity. No significant interactions were detected for any of the variables ( $\mathrm{pH}: p=0.9653$; EC: $p=0.3944)$.

\begin{tabular}{lcc|cc}
\hline $\begin{array}{l}\text { Substrate } \\
\text { Treatment }\end{array}$ & \multicolumn{2}{c|}{$\begin{array}{c}\text { Electrical conductivity } \\
(\mathrm{mS} / \mathrm{cm})\end{array}$} & & pH \\
\hline & Unsterilized & Sterilized & Unsterilized & Sterilized \\
R. ericae & $3.06 \pm 1.34$ & $2.31 \pm 0.84$ & $4.97 \pm 0.16$ & $3.75 \pm 0.26$ \\
Meliniomyces sp. & $3.79 \pm 1.27$ & $1.79 \pm 0.42$ & $4.79 \pm 0.34$ & $3.76 \pm 0.20$ \\
$P$. fortinii & $2.74 \pm 0.32$ & $3.27 \pm 0.44$ & $4.78 \pm 0.30$ & $3.69 \pm 0.23$ \\
Control & $2.07 \pm 0.59$ & $2.27 \pm 0.41$ & $4.81 \pm 0.20$ & $3.76 \pm 0.10$ \\
\hline
\end{tabular}


a)

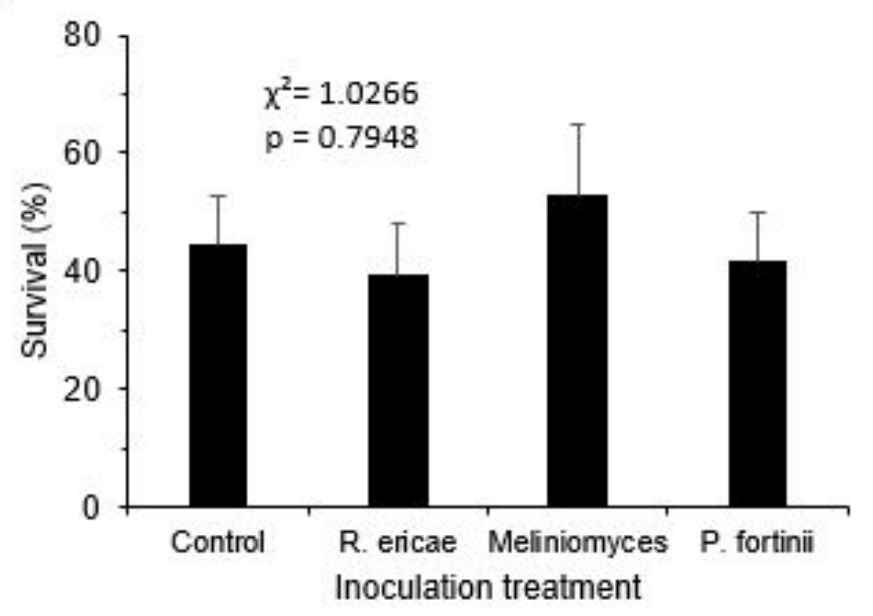

b)

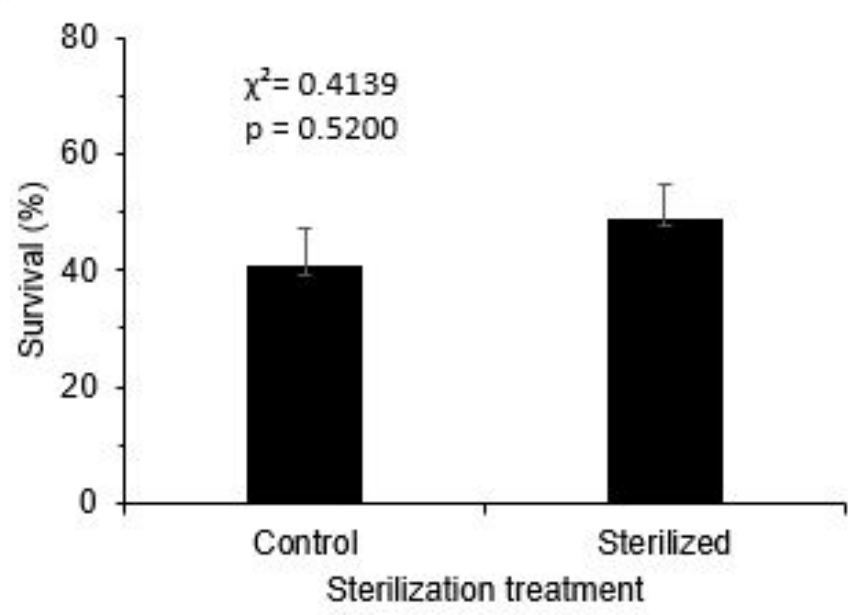

Figure 1. Survival rates of cuttings according to (A) Inoculation treatment (P. fortinii:

Phialocephala fortinit, R. ericae: Rhizoscyphus ericae) and (B) Sterilization treatment (Control: Unsterilized waste rock, sterilized: Sterilized waste rock) (mean \pm standard error, for each factor, no statistically significant effect was detected, $p<0.05$; logistic regression analysis). 
a)

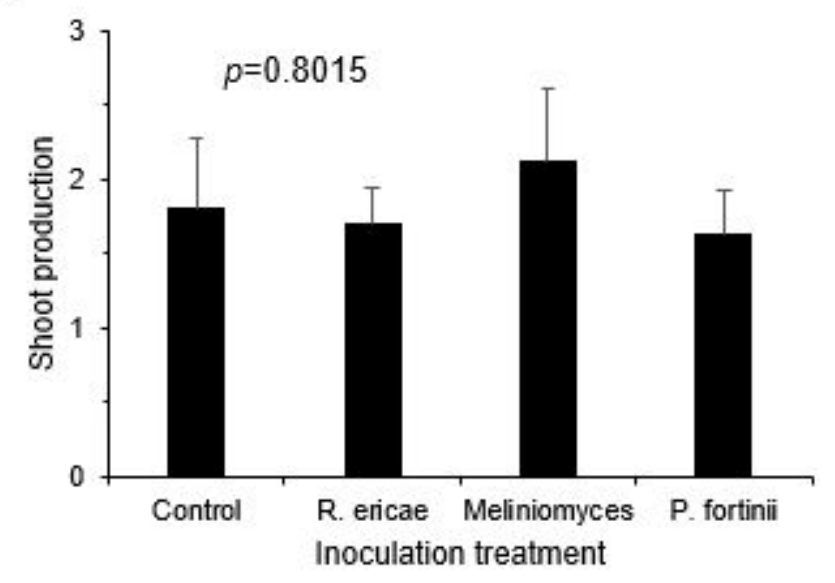

b)

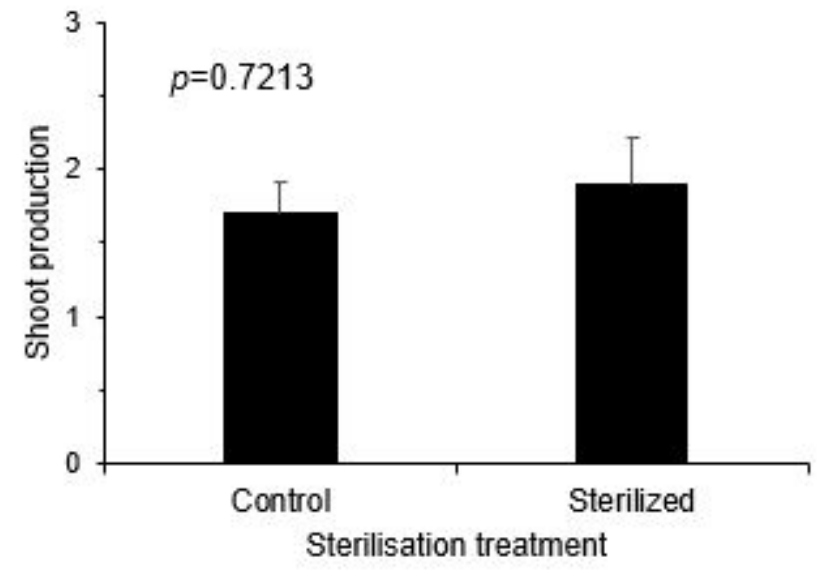

Figure 2. Shoot production per cutting of S. planifolia in (A) Inoculation treatment $(P$. fortinii: Phialocephala fortinii, R. ericae: Rhizoscyphus ericae) and (B) Sterilization treatment (Control: Unsterilized waste rock, sterilized: Sterilized waste rock) (mean \pm standard error; for each factor, no statistically significant effect was detected, $p<0.05$; Tukey test, $p<0.05)$. 
a)

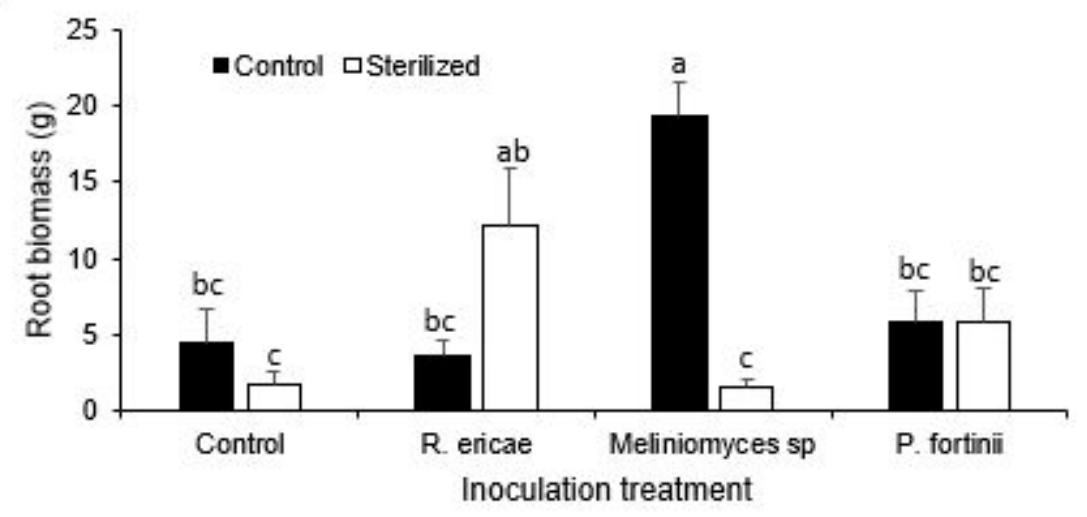

b)

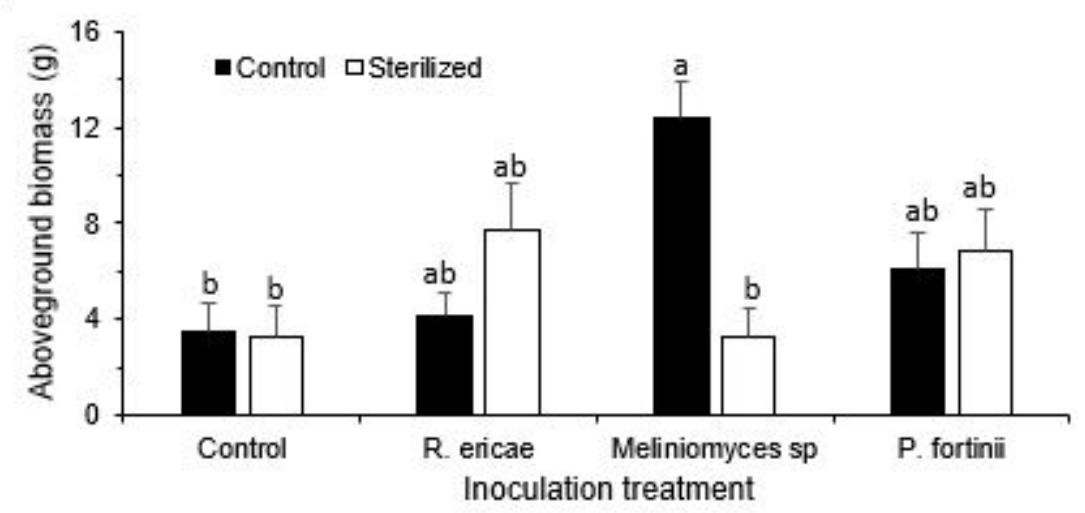

Figure 3. A) Root biomass, B) Aboveground biomass from cuttings of S. planifolia in the Inoculation treatment in Sterilization treatment (mean \pm standard error). Black bars: control: unsterilized waste rock, White bars with dark outlines: sterilized: sterilized waste rock. Different lowercase letters indicate the presence of significant differences (Tukey test, $p<0.05)$. 
- Control $\square$ Sterilized waste rock

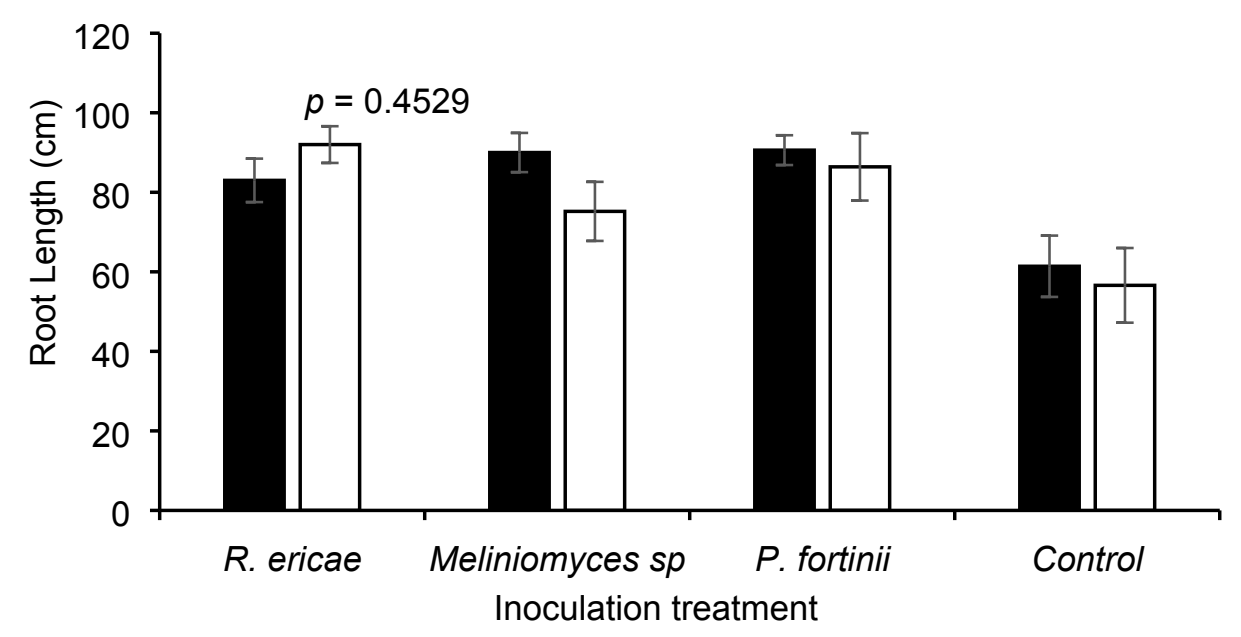

Figure 4. Root length of shoots from cuttings of $S$. planifolia in the Inoculation treatment in Sterilization treatment (mean \pm standard error; for each factor, no statistically significant interaction was detected, $p<0.05$; Tukey test, $p<0.05$ ). Black bars: control: unsterilized waste rock, White bars with dark outlines: sterilized: sterilized waste rock. 


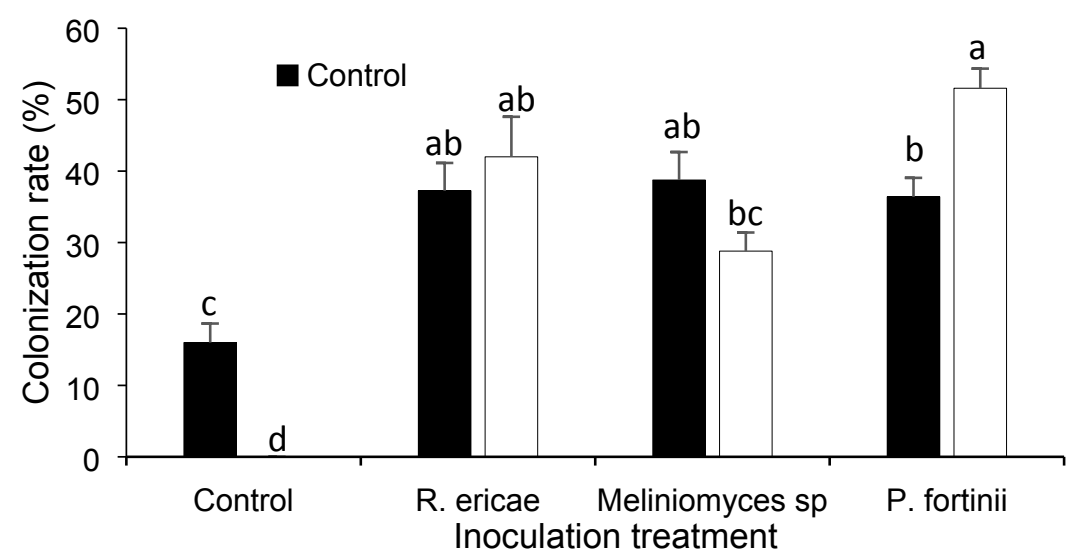

Figure 5. Colonization rate of shoots from cuttings of S. planifolia in the Inoculation treatment in Sterilization treatment (mean \pm standard error). Black bars: control: unsterilized waste rock, White bars with dark outlines: sterilized: sterilized waste rock. Different lowercase letters indicate the presence of significant differences (Tukey test, $p$ $<0.05)$. 